\title{
Atenção Humanizada em um Grupo de Cuidados Essenciais ao Paciente Oncológico e Seu Cuidador
}

\author{
Bueno, Camila da Silva; Silva, Ana Caroline Azevedo; Brito, Christina May Moran de; \\ Barbosa, Lilian Paula Garrido; Santos, Patricia Cunha \\ Icesp — camila.bueno@icesp.org.br
}

Introdução: Segundo dados da O.M.S., o Brasil apresentou 437 mil novos casos de câncer no ano de 2012. Apesar das abordagens atuais de tratamento, as sequelas que podem advir do câncer - como prejuízo nas habilidades motoras, cognitivas e sensoriais - podem comprometer a independência funcional do indivíduo e requerem intervenções específicas, individualmente ou em grupo. o atendimento em grupo tem caráter terapêutico e educacional e possibilita a orientação de pacientes e familiares. ao propiciar acolhimento e escuta, a intervenção é delineada, visando a aderência efetiva às orientações e manutenção do ganho. Objetivos: Orientar o paciente e/ou seu cuidador na adequação de suas atividades de vida diária para promover conforto e melhora da independência funcional. Métodos: o paciente é avaliado no ambulatório de Fisiatria e encaminhado ao grupo, caso sejam constatados os seguintes critérios: capacidade funcional reduzida, evolução e prognóstico reservado da doença, dependência de cuidados e condições socioeconômicas que inviabilizem a participação em um programa de Reabilitação convencional. Os atendimentos do grupo são realizados por psicólogo, enfermeiro, terapeuta ocupacional e fisioterapeuta. São agendados dois encontros, quinzenalmente e com duração de duas horas cada. no primeiro encontro, os participantes se apresentam e descrevem o seu entendimento e expectativas quanto ao quadro clinico e sua dinâmica com o cuidador. a partir de seus relatos, enfocam-se as orientações e estratégias que viabilizem mudanças ou adaptações a fim de otimizar o cuidado. São fornecidos materiais informativos que tratam dos temas abordados. no segundo atendimento, verifica-se a apreensão das orientações discutidas, esclarecendo-se dúvidas e propiciando trocas de experiências quanto à nova postura adotada. Verifica-se se os objetivos foram atingidos ou se há indicação para encaminhamento para continuidade do atendimento ou para outros serviços. Caso a demanda se mantenha, um terceiro encontro é agendado. Resultado: Até o momento, 65 pacientes (26 mulheres e 39 homens), com média de idade de 61 anos e seus cuidadores foram convocados para o grupo. com relação ao diagnóstico primário, 18,46\% apresenta câncer de próstata; $15,38 \%$ de mama; $13,84 \%$, de sistema nervoso central; $10,76 \%$, câncer ósseo; $9,23 \%$ de trato gastrointestinal; $4,61 \%$ de cabeça e pescoço; $4,61 \%$ trato genitourinário; $4,61 \%$ de pulmão; $3,07 \%$ de pele; 3,07\% ginecológico; $1,53 \%$ sem localização especifica. a assiduidade e o atingimento dos objetivos neste grupo, até o momento, foram de $68 \%$. Conclusões: o cuidado de reabilitação realizado na forma de grupo de orientação para pacientes que demandem cuidados essenciais traz benefícios a pacientes e cuidadores, e constitui estratégia alternativa viável para pacientes com o perfil descrito.

Bueno, Camila da Silva; Silva, Ana Caroline Azevedo; Brito, Christina May Moran de; Barbosa, Lilian Paula Garrido; Santos, Patricia Cunha. Atenção Humanizada em um Grupo de Cuidados Essenciais ao Paciente Oncológico e Seu Cuidador. In: Anais do Congresso Internacional de Humanidades \& Humanização em Saúde [= Blucher Medical Proceedings, num.2, vol.1]. São Paulo: Editora Blucher, 2014. ISSN 2357-7282 DOI 10.5151/medpro-cihhs-10704 